\title{
A test of the association between the initial surge in COVID-19 cases and subsequent changes in financial risk tolerance
}

\author{
Wookjae Heo
}

\author{
Division of Health and Consumer Sciences, South Dakota State University, \\ Brookings, South Dakota, USA \\ John E. Grable \\ Department of Financial Planing, Housing, and Consumer Economics, \\ University of Georgia, Athens, Georgia, USA, and
}

Abed G. Rabbani

Department of Personal Financial Planning, University of Missouri, Columbia, Missouri, USA

\begin{abstract}
Purpose - The purpose of this paper is to provide an estimate of the degree to which financial risk tolerance changed in relation to the initial surge of COVID-19 cases in the US.

Design/methodology/approach - Data from a large sample of investors and other consumers covering the period beginning April 2019 and ending in early May 2020 were used to estimate aggregate levels of financial risk tolerance and to determine if the willingness to take financial risk changed across five distinct periods in relation to the spread of COVID-19.

Findings - A general reduction in aggregate levels of financial risk tolerance was observed during the initial peak of COVID-19 period and the subsequent declaration of a pandemic, with the most significant drop in risk tolerance being exhibited by those who were 25 years of age or younger.

Practical implications - The findings from this study - primarily that in terms of FRT, the COVID-19 pandemic impacted young people disproportionately - suggest that in addition to helping young people feel comfortable in terms of their personal health situation and access to employment and health insurance, policy makers, financial service firms and financial literacy educators should provide information and guidance to young people regarding why being willing to take financial risks is important and how FRT corresponds to the proper functioning of the investment markets.

Originality/value - A data-drive methodology was utilized in this study to define the periods. This approach was taken due to the lack of defined and published pandemic interval periods specific to COVID19. However, the findings based on the data-driven methodology bring practical implications such as young people are sincerely considered in the catastrophic situation.
\end{abstract}

Keywords COVID-19, Financial risk tolerance, Risk aversion

Paper type Research paper

\section{Introduction}

What has come to be known as the COVID-19 pandemic is thought to have started in Wuhan, Hubei Province, China, in late 2019 (CDC, 2020a). The COVID-19 virus is a new coronavirus strain. While coronavirus is relatively common across animal species, this particular strain of coronavirus spreads quickly with potentially severe outcomes for those with serious underlying medical conditions (e.g. heart disease, lung disease and diabetes).

The COVID-19 virus spread from China to almost every country in the world by early March 2020. By the middle of March 2020, all the 50 US states had reported cases of COVID-19. In response to the threat caused by the worldwide situation, the World Health Organization characterized COVID-19 as a pandemic. Historically, COVID-19 is the fourth global pandemic in
Received 3 June 2020

Revised 22 July 2020 Accepted 2 August 2020 
$\mathrm{RBF}$

13,1

4

the past century, with the difference being that the other pandemics were related to influenza. By March 13, 2020, nearly every US state had imposed restrictions to slow the spread of the virus in response to President Trump's emergency declaration. The state restrictions were akin to self-imposed economic sanctions. The result was a significant and sudden drop in gross domestic product and an increase in nationwide unemployment. Initially, the investment markets fell as investors reevaluated their risk and return expectations.

There are numerous reasons to believe the COVID-19 pandemic - and the response to the pandemic - altered the degree to which individuals, on average, are willing to engage in behaviors that are both uncertain and offer a possibility of a financial loss or gain. One reason to anticipate a decline in measured risk tolerance is the speed at which news of the COVID-19 virus spread among the population. It has been estimated that at least one out of four American investors relies on social media when making portfolio choices (Reidy, 2013). When social media turns negative, as it did during the pandemic, this could influence the way investors establish market expectations, which might then reduce investment sentiment. Another reason to believe that the willingness of investors to take risk fell in reaction to COVID-19 can be found in data from the global financial crisis. Vogenberg and Cutts (2009) reported that financial strain alters household financial stability and well-being. In times of significant crises, consumers sometimes dramatically change their behavior. In terms of health care, Vogenberg and Cutts reported that some patients stopped receiving critical care needs and/or postponed health care spending during the global financial crisis. It is possible that a similar reaction occurred among investors as COVID-19 cases surged in early 2020. Specifically, it is easy to imagine that investors' willingness to take risks fell in tandem with the economic strain caused by country-wide economic shutdowns resulting from the rapid increase in COVID-19 cases.

It is also possible that the financial risk tolerance of investors during the initial stages of the COVID-19 pandemic did not fluctuate dramatically, either downward or upward. There is evidence from the global financial crisis to support this possibility. Consider the work of Gerrans et al. (2015). These researchers tracked the risk tolerance of an international sample during a three-year period of the global financial crisis (2007 through 2009). They noted that even in the presence of economic uncertainty, financial risk tolerance remained relatively stable in the aggregate. Gerrans et al. reported that an investor's willingness to take financial risk exhibits much less elasticity than the popular view might suggest.

The purpose of this paper is to contribute to the literature by providing an estimate of the degree to which financial risk tolerance changed in relation to the initial surge of COVID-19 cases in the US. Using a large sample of investors and other consumers, data from the period beginning April 2019 and ending in early May 2020 were used to estimate aggregate levels of financial risk tolerance and to evaluate the degree to which the willingness to take financial risk across five distinct periods changed. A particular focus of the study was on distinguishing changes in risk tolerance among age cohorts. Findings from this study suggest that aggregated risk-tolerance data may hide changing risk attitudes of investors in different age categories. Results from this study indicate that the initial surge in COVID-19 cases had the greatest negative impact on young investors and consumers, with the greatest drop in financial risk tolerance corresponding to those aged 25 years of age or younger.

\section{Background}

The study of financial risk tolerance (FRT), which is defined broadly as a person's willingness to engage in a financial behavior, in which the outcome is both uncertain and potentially negative (Nobre and Grable, 2015) has increased exponentially over the past three decades. The study of risk attitudes in the economics and finance literature has traditionally been 
conducted with a revealed preference lens, in which risk tolerance is not assessed directly but is instead measured as risk aversion (Walls and Dyer, 1996). Measures of risk aversion are commonly used in portfolio models to help select efficient portfolios. Even though it is a normative recommendation, few financial advisors or investors evaluate risk aversion directly as a means of estimating utility functions. Nearly all financial advisors and those who provide investment and financial advice to consumers measure FRT. In some cases, regulatory agencies require financial advisors to measure FRT explicitly.

Regardless if an individual's willingness to take financial risk is measured as risk aversion or risk tolerance, an important assumption imbedded in nearly all assessment methodologies is the notion that risk attitudes are stable. This assumption is indeed an important one because if FRT, as an input into the portfolio selection process, actually varies systemically by time or circumstance, the suitability of a selected choice that entails risk may decline as FRT changes.

Some have noted that FRT is subject to change, especially in light of significant market disruptions (Guiso et al., 2013; Hoffmann et al., 2013; Yao and Curl, 2011). Those who believe that FRT is subject to meaningful variability argue that market volatility drives how investors establish risk and return expectations. When the markets are particularly volatile or when economic events become uncertain, investors and consumers are thought to become less willing to take financial risk. Consider the results from a study undertaken by Clarke and Statman (1998). They found that FRT moves in tandem with the sentiment of financial newsletter authors. Similarly, Yao et al. (2004) reported that FRT varies with pricing patterns in the stock market. In general, those who believe that FRT can change argue that investors fall into a projection bias trap by altering their willingness to take a financial risk based on current market conditions.

Others believe that what some have reported in the literature as variability in FRT is simply a tight dispersion around a stable mean. Van de Venter et al. (2012) reported that while they did observe variability in FRT across several time periods, any changes were purely short-term variations and not particularly large. This observation was validated by Guillemette and Finke (2014). Similarly, when evaluating FRT in relation to changes in stock market conditions caused by the great recession, Rabbani et al. (2017) noted that changes in FRT, while present in their data, were modest and generally not large enough to warrant a change in portfolio holdings. Hoffmann et al. (2013), in a similar vein, argued that even when FRT appears to change, the variation is temporary.

One consistent finding emerges from the literature: FRT is not a perfectly stable trait. As noted above, there is less agreement regarding the degree of variability in FRT. Some argue that any noticeable changes, either at the individual or aggregate level, will rarely ever be large enough to matter in practice. That is, the effect size of a noticed difference will be small. Others believe that changes in FRT may be subject to large variations. To date, there have been few real-life situations in which these arguments could be tested. Data gathered during the great recession represent one period of time in which researchers were able to gather FRT data and correlate FRT assessment scores to market conditions, which explains why nearly all reports of FRT variability stem from analyses of data from the global financial crisis. What is missing in the literature is empirical evidence of FRT in relation to nonmarket crises. The COVID-19 pandemic does provide a true to life laboratory for the study of FRT. The COVID-19 pandemic is unique in being an event that not only caused a downturn in the economy and increased investment market volatility but also inflicted tremendous pressure on the social systems underlying all aspects of US life. The present study was undertaken to add to the existing literature by documenting the degree to which aggregate levels of FRT changed in response to the initial surge in COVID-19 cases reported in the US. 


\section{$\mathrm{RBF}$}

13,1

\section{Methods \\ Data}

Data for this study were gathered cross-sectionally over the period of April 2019 through early May 2020 from an open-access online survey hosted by the University of Missouri, Department of Financial Planning (http://pfp.missouri.edu/research_IRTA.html). The survey was open to anyone with Internet access (e.g. consumers, educators, financial counseling and planning practitioners, researchers, etc.). The survey has been widely used in previous research. Both Google ${ }^{\mathrm{TM}}$, Yahoo ${ }^{\mathrm{TM}}$ and Bing ${ }^{\mathrm{TM}}$ show the survey as a primary search outcome associated with phrases like "financial risk tolerance assessment." In addition to being highlighted in Internet search engines, information about the survey site has been advertised as a no cost financial risk-assessment tool among financial literacy educators (e.g. Rabbani et al., 2018) and among those in the media (e.g. Robbins, 2014).

The survey asked respondents to answer 13 questions from an FRT questionnaire developed by Grable and Lytton (1999). The scale was developed to assess an investor's willingness to take financial risk. The scale represents a propensity or elicitation measure of FRT. The scale was conceptualized using classical test theory procedures, and in this sense, the scale shares aspects with other propensity measures [1]. In this study, scores on the scale ranged from 13 to 41, with higher scores indicating higher (lower) risk tolerance (aversion). The reliability and validity of the scale have been widely reported in the literature, with scores meeting minimum reliability standards across age groups (University of Virginia Library, 2020), with the highest reliability estimates being associated with older cohorts. Scores from the scale are also known to be associated with portfolio choices and general risk-taking behavior (Grable et al., 2019; Grable and Schumm, 2010; Kuzniak and Grable, 2017).

Data were coded daily, which made it possible to track aggregate risk attitudes on a continuous basis. Data from a total of 68,870 respondents were used in this study. Although the sample was not representative of the larger US population, the sample was nonetheless diverse. Approximately $54 \%$ and $46 \%$ of participants were men and women, respectively. The modal age category was under 25 years, with the majority of participants being married at the time of the survey. The attained educational profile of those in the sample ranged from a high school diploma to a graduate or higher degree. Household income was widely distributed, ranging from less than $\$ 25,000$ to more than $\$ 100,000$. The majority of participants reported household income greater than $\$ 50,000$.

\section{Data analysis}

The sample was split into five groups based on the degree to which the number of cases of COVID-19 was reported in the US. Using data that were date matched to the number of COVID-19 cases tracked by the CDC (2020b), the composition of each group was determined based on CDC (2020c) guidelines: (1) no known cases or intermittent cases (Period 0: from April 29, 2019 to February 26, 2020); (2) recognition of cases (Period 1: from February 27, 2020 to March 14, 2020); (3) wave initiation (Period 2: from March 15, 2020 to April 1, 2020); (4) case acceleration (Period 3: from April 2, 2020 to April 6, 2020) and (5) case deceleration and stabilization (Period 4: from April 7, 2020 to May 4, 2020). The periods were estimated by observing the trend data from Figure 1 [2]. Figure 1 shows the number of daily cases over the period January 27, 2020 to May 4, 2020. These data were used to determine the beginning and ending dates for group inclusion.

COVID-19 case data were matched to each respondent's date of survey completion. The baseline group included respondents who completed a survey between April 29, 2019 and February 26, $2020(n=54,333)$, which represented a period in which there were very few known COVID-19 cases in the US. The second group $(n=4,207)$ included respondents who completed a survey between February 27 (i.e. the date of the first reported COVID-19 case in 


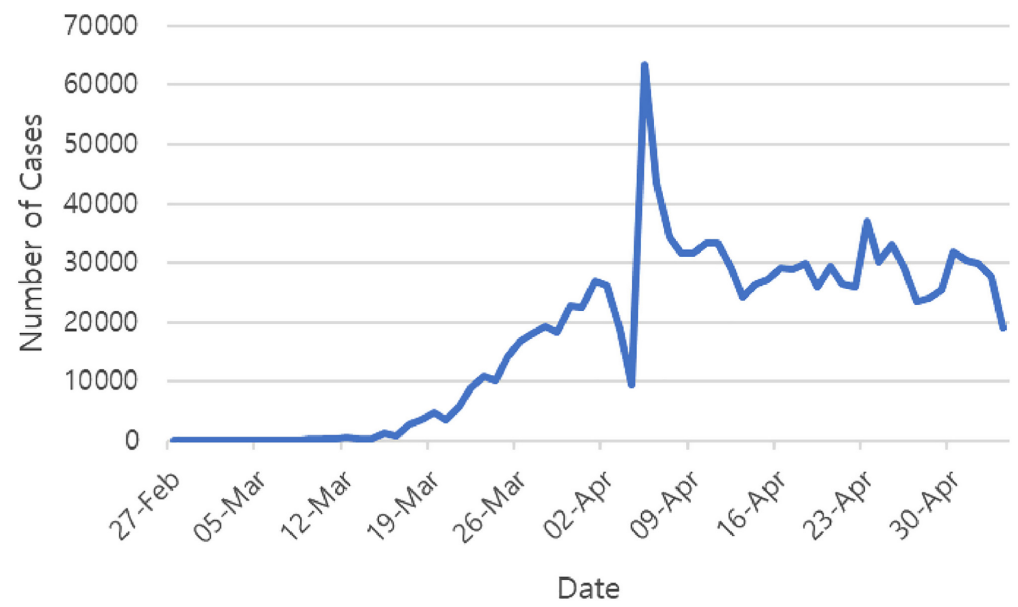

Impact of

COVID-19

the US) and March 14. The third group $(n=2,916)$ included those who completed a survey during the period when the COVID-19 virus was spreading quickly (as proxied by the number of reported cases). This period, as shown in Figure 2, lasted from March 15 through April 1 [3]. A regression was estimated to confirm that this period of time represented an interval of linear acceleration in the number of cases. The regression estimate was based on the following model:

$$
\text { Cases }=\alpha+\beta^{*} \text { date }+e
$$

The linear relationship was confirmed at the $p<0.001$ level.

The fourth group $(n=890)$ included those who completed a survey from April 2 to April 6 . This time period represented the peak in cases as reported by the CDC during the periods of

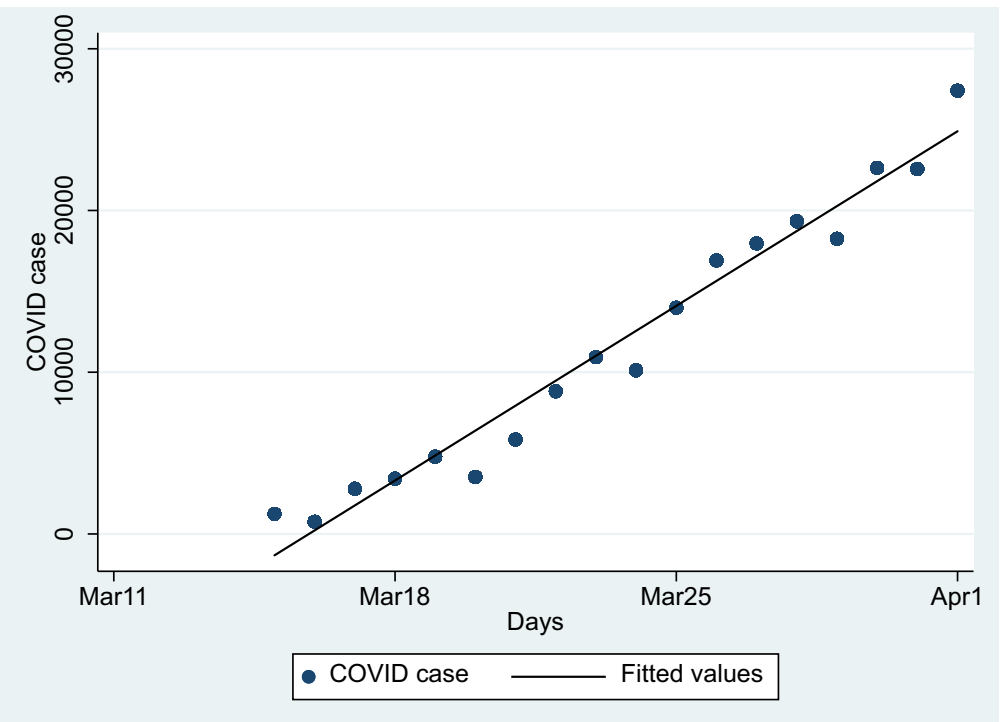

Figure 2. Estimated linear acceleration of COVID-

19 cases over the period March 15 to April 1 
$\mathrm{RBF}$

13,1

8 analysis. The last group $(n=6,524)$ completed the survey during the period of COVID-19 case deceleration and stabilization (April 7 through May 4 [the last day of initial data collection]). During this period, the average number of daily cases was estimated to be approximately 28,869 ( $\mathrm{SD}=3,690$ ), which meant that the number of cases varied around the mean between +1 and -1 standard deviation. As shown in Figure 3, the number of standardized cases was close to the average number of cases during this period.

A trend analysis was used to estimate the degree to which FRT changed across the periods of study. It was hypothesized that a decrease in aggregate levels of FRT would be observed among the groups as the COVID-19 pandemic worsened in the US. The trend analysis was validated using linear estimations to determine the extent to which FRT, across the groups, was associated with the number of COVID-19 cases. The remainder of this paper describes the demographic characteristics of the sample and the findings from the trend and linear estimation analyses.

\section{Results}

Table 1 provides information about the demographic profile of those in the sample. The sample was skewed toward those who were married, male and younger. Given the age profile of respondents, it is not surprising that the attained education of those in the sample was at the some college or less level. Household income was distributed broadly from less than $\$ 25,000$ to over $\$ 100,000$. The average and standard deviation of the FRT scale score were 27.22 and 4.99, respectively, which was indicative of a moderate level of risk tolerance (i.e. respondents were neither risk seekers nor risk avoiders). The Cronbach's alpha associated with the measure of FRT, based on data from 68,870 respondents, was 0.70 . It is important to note, however, that reliability varied by age, with the highest alpha scores exhibited by those over age $75(0.87)$ and the lowest alpha scores corresponding to those under age $34(0.70)$. Given the purpose of the study, the global mean alpha score was deemed to be acceptable (University of Virginia Library, 2020).

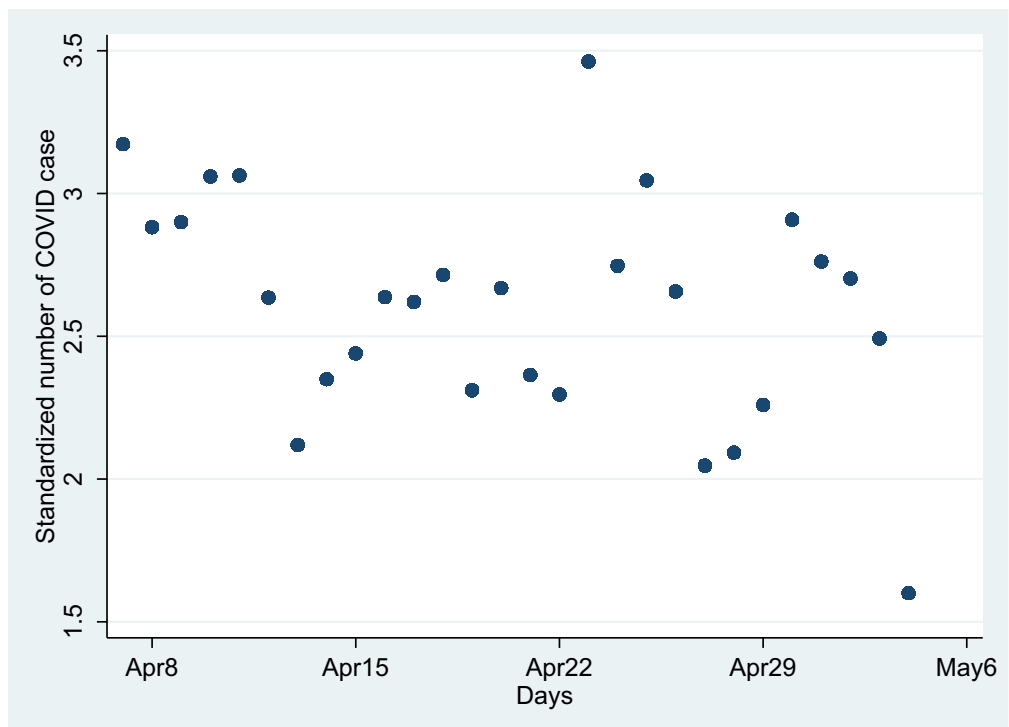

Figure 3.

Number of cases between April 7 and May 4 


\begin{tabular}{|c|c|c|c|c|c|}
\hline & Frequency & $\%$ & $M$ & SD & Impact of \\
\hline Gender (male) & 37,393 & 54.37 & & & \\
\hline \multicolumn{6}{|l|}{ Age } \\
\hline Under 25 & 53,219 & 77.27 & & & \\
\hline $25-35$ & 7,501 & 10.89 & & & \\
\hline $35-45$ & 3,914 & 5.68 & & & 9 \\
\hline $45-55$ & 2,135 & 3.10 & & & \\
\hline $55-65$ & 1,278 & 1.86 & & & \\
\hline 65-75 & 549 & 0.80 & & & \\
\hline Over 75 & 274 & 0.40 & & & \\
\hline \multicolumn{6}{|l|}{ Education } \\
\hline Lower than high school & 26,843 & 39.07 & & & \\
\hline High school graduate & 13,496 & 19.64 & & & \\
\hline Some college & 9,972 & 14.51 & & & \\
\hline Associate's degree & 3,813 & 5.55 & & & \\
\hline Bachelor's degree & 8,896 & 12.95 & & & \\
\hline Graduate or higher & 5,693 & 8.29 & & & \\
\hline \multicolumn{6}{|l|}{ Household income } \\
\hline$<\$ 25 \mathrm{k}$ & 18,259 & 26.78 & & & \\
\hline$\$ 25 \mathrm{k}-\$ 50 \mathrm{k}$ & 12,651 & 18.56 & & & \\
\hline$\$ 50 \mathrm{k}-\$ 75 \mathrm{k}$ & 12,206 & 17.90 & & & \\
\hline$\$ 75 k-\$ 100 k$ & 8,184 & 12.00 & & & \\
\hline$>\$ 100 \mathrm{k}$ & 16,877 & 24.75 & & & \\
\hline \multicolumn{6}{|l|}{ Marital status } \\
\hline Married & 54,281 & 78.95 & & & \\
\hline Never married & 3,584 & 5.21 & & & \\
\hline Living with others & 8,512 & 12.38 & & & \\
\hline Separated/divorced & 1,356 & 1.97 & & & \\
\hline Sharing house & 395 & 0.57 & & & Table 1 \\
\hline Widowed & 628 & 0.91 & & & Demographic profile \\
\hline Financial risk tolerance & & & 27.22 & 4.99 & of respondents \\
\hline
\end{tabular}

\section{Trend analysis results}

As shown in Table 2 and Figure 4, no noticeable change in the average level of FRT was noted over the five periods of analysis. The change in FRT from the high to the low was less than one point. However, the average FRT score only tells a portion of the story. Risk-tolerance scores were skewed. Although the average FRT score did not vary dramatically, what did happen is that from period 1 to period 4, respondents were more apt to report a preference for less financial risk. A variance test confirmed that periods 1 and 3 showed the greatest change in score distributions ( $F=1.05, p<0.05$ and $F=1.13, p<0.05$, respectively). While many

\begin{tabular}{rrrrrr}
\hline & $n$ & Days & $\begin{array}{c}\text { COVID-19 cases/day } \\
M(\mathrm{SD})\end{array}$ & $\begin{array}{c}\text { Risk tolerance } \\
M(\mathrm{SD})\end{array}$ & \\
\hline Period 0 & 54,333 & 304 & & $27.26(5.02)$ & Table 2. \\
Period 1 & 4,207 & 17 & $120.22(135.26)$ & $27.24(4.90)$ & Number of daily \\
Period 2 & 2,916 & 18 & $11960.62(8656.91)$ & $27.32(5.05)$ & COVID-19 cases and \\
Period 3 & 890 & 5 & $32305.61(18071.49)$ & $27.16(4.75)$ & risk tolerance scores \\
Period 4 & 6,524 & 28 & $28869.22(3690.13)$ & $26.87(4.81)$ & per period \\
\hline
\end{tabular}




\section{$\mathrm{RBF}$ \\ 13,1}

10

Figure 4.

Comparison of FRT scores across periods

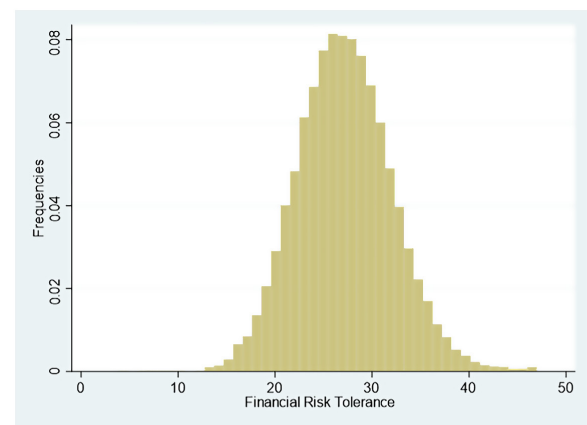

Period $0(n=54,333)$

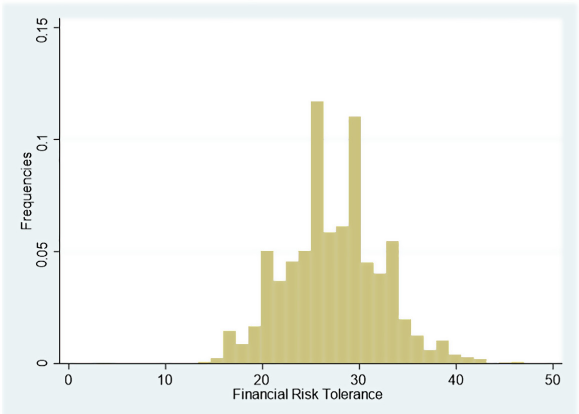

Period $2(n=2,916)$

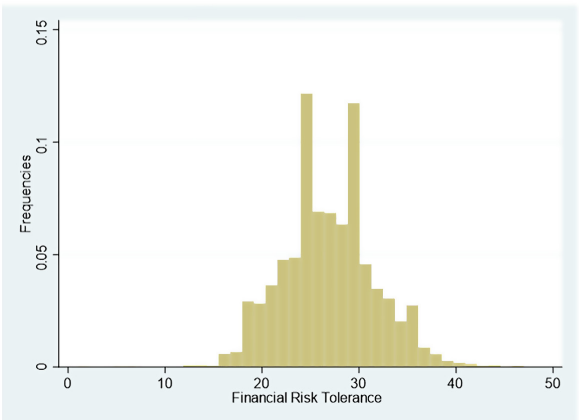

Period $4(n=6,524)$

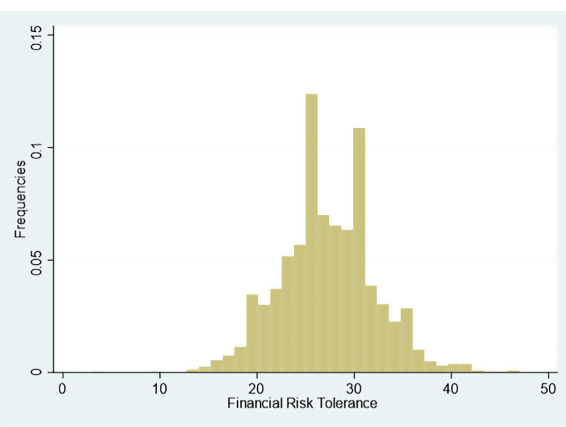

Period $1(n=4,207)$

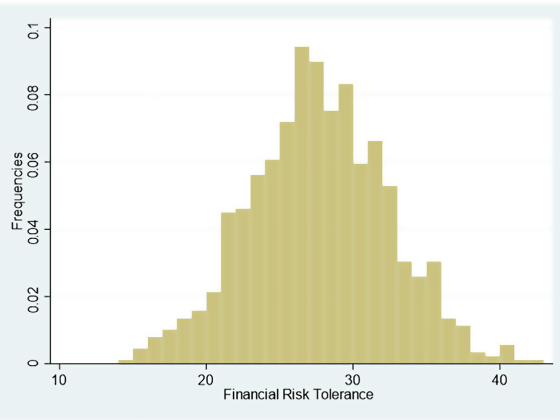

Period $3(n=890)$

respondents were observed to hold a high tolerance for financial risk, at period 4, there was a large shift among respondents toward preferring low risk response choices. The downward shift in scores was statistically significant, $t=1.69, p<0.01$. This shift, however, was disguised by the average risk score. As an example, a large number of respondents reported having an average willingness to take financial risk during periods 1 and 2 . This can be seen in the peaks in the distributions corresponding to periods 1 and 2 in Figure 4. The resulting average score caused by these peaks effectively masked the general migration to a lower level of FRT in the sample.

Figure 5 shows how average FRT scores varied from the beginning of the COVID-19 crisis through May 5, 2020. A statistically significant relationship between these two variables was 
observed. The correlation between the COVID-19 variable and FRT, on a daily basis (68 days) between period 1 and period 4, was $-0.37(p=0.002)$.

In the aggregate, FRT scores fluctuated within a narrow range over the periods of analysis, with three exceptions. During the early stages of the crisis, FRT scores skewed slightly higher. However, as the number of COVID-19 cases escalated, and more media attention was focused on the worsening health and economic outcomes associated with the virus, FRT scores fell, with an average low score reported approximately seven weeks after the first COVID-19 case was reported to the CDC. FRT scores exhibited a meaningful decline from period 2 to period 4 .

A regression model based on questionnaire data from 10,330 respondents was estimated to evaluate the decrease in FRT from period 2 through the end of period 4 . The results from the test are shown in Table 3 . The model and the coefficient $(b=-0.01, p<0.001)$ were statistically significant. The amount of explained variance was low; however, this was not unexpected given the variables in the model. The purpose of the analytic estimation was to identify the daily linear trend. The linear estimation was similar to an autocorrelation check without any explanatory variables, which resulted in the small $R^{2}$. It was determined that FRT fell during each day of the pandemic. The decrease was not dramatic or large, but it was consistent.

An additional regression model was estimated as a robustness check. This model used the average daily change in FRT scores as the independent variable over the same period. Data were transformed into time-series data with the average of all responses on a given day used as one observation. The results, as shown in Table 4, represent 51 days across the periods of analysis. A similar pattern of decreasing FRT was observed. The amount of explained

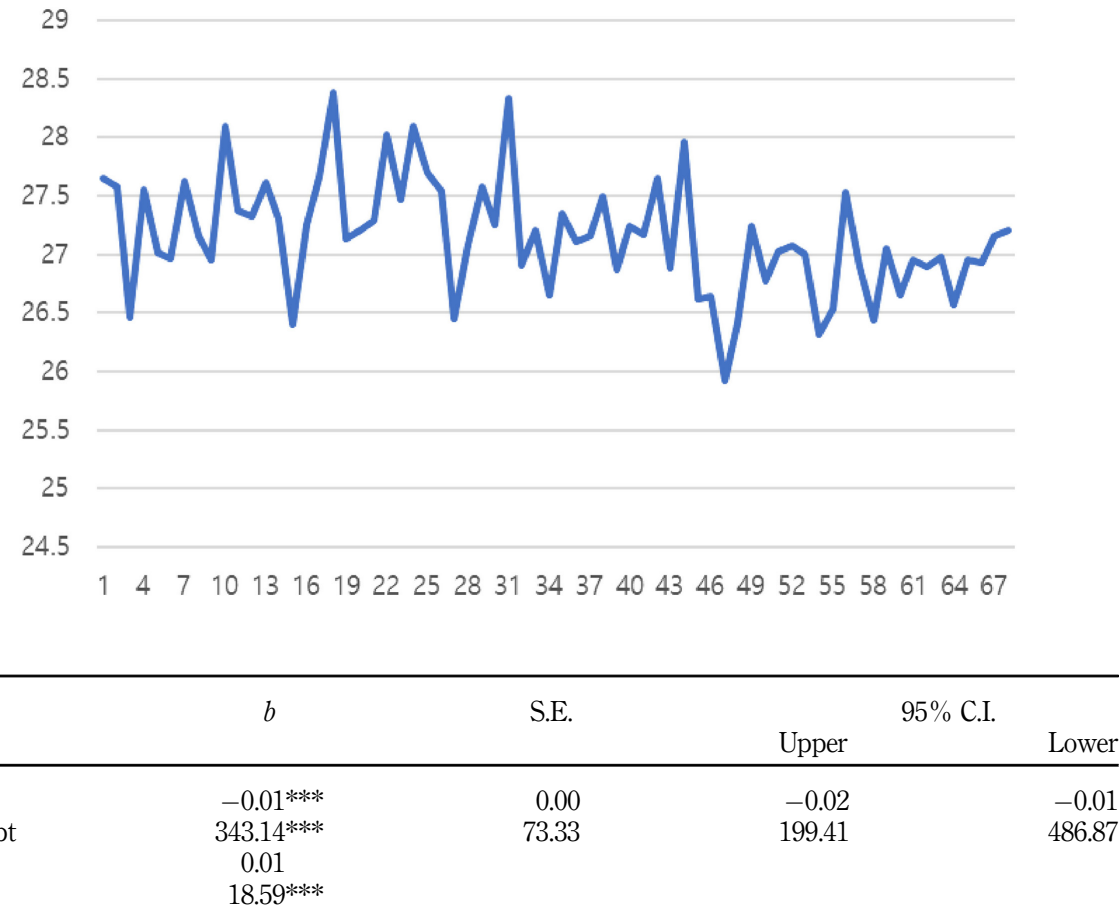

\begin{tabular}{lcccr}
\hline & $b$ & S.E. & Upper & $95 \%$ C.I. \\
& & & -0.02 & Lower \\
\hline Days & $-0.01^{* * * *}$ & 0.00 & 199.41 & -0.01 \\
Intercept & $343.14^{* * * *}$ & 73.33 & & 486.87 \\
$R^{2}$ & 0.01 & & & \\
$F$ & $18.59^{* * * *}$ & & &
\end{tabular}

Note(s): The significant level: *** $p<0.001$

Figure 5.

Daily average observed FRT scores

Linearity check from period 2 to period 4 $(n=10,330)$ 
$\mathrm{RBF}$

13,1

\section{2}

Table 4.

Linearity robustness check from period 2 to period 4 using daily average FRT scores $(n=51$ days $)$ variance associated with the model was robust. Figure 6 shows how FRT declined during the COVID-19 pandemic.

It was thought that one explanation for the observed downward trend in FRT scores may have been related to the age of those in the sample. Although the age of respondents ranged from under age 25 to over age 75 , the sample was skewed toward younger respondents. The literature is replete with evidence that FRT differs based on the age of the person making a risky decision. It is generally thought that older individuals prefer less financial risk, whereas younger individuals prefer (and to some extent have the capacity for) greater risk (Cardak and Martin, 2019; Hartnett et al., 2019; Koekemoer, 2018; Pinjisakikool, 2017), although there is some evidence suggesting an opposite relationship (Wang and Hanna, 1998). Given that an association between FRT and age is thought to exist, a series of tests were undertaken to determine if the observed changes in FRT were generalizable across the sample or whether changes in FRT scores represented an age cohort effect. Respondents were grouped into one of four age categories to address this question. The age sub-groups are shown in Table 5. The last row in the table represents the total number of respondents, per sub-group, in periods 2,3 and 4 (i.e. the periods in which the most noticeable changes in FRT were observed).

An age cohort difference was noted. As shown in Table 6 and Figure 7, a significant decreasing trend in FRT scores from period 2 to period 4 was observed only for those respondents in the under 25 age group. In fact, the under 25 age model was the only one that

\begin{tabular}{lcccr}
\hline & $b$ & S.E. & Upper & $95 \%$ C.I. \\
\hline Days & & & -0.03 & Lower \\
Intercept & $-0.02^{* * *}$ & 0.00 & 204.40 & -0.01 \\
$R^{2}$ & $391.34^{* * *}$ & 93.02 & & 578.27 \\
$F$ & 0.24 & & & \\
\hline
\end{tabular}

Figure 6.

FRT scores showing a downward tendency during the COVID19 pandemic (aggregated average data)

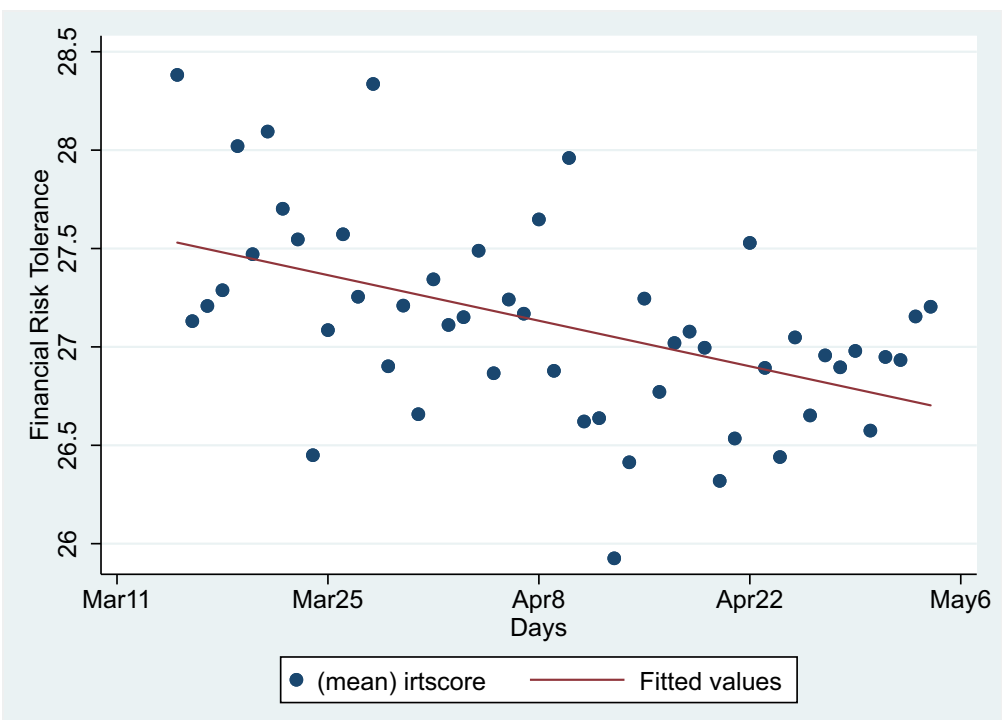


offered a significant model fit. Because the sample sizes were different across all age groups, and the sample size for the oldest respondents (over 65) was relatively low, another regression was estimated using a bootstrap methodology to check the significance of the linearity finding and the model fit. The results matched the original result.

A further test was conducted to determine whether those in the under 25 age group were primarily students or whether the group included likely investors and other consumers (in addition to students). As shown in Table 7, the distribution of the 7,709 respondents classified as under age 25, between periods 2 and 4, was much broader than one would expect had this sub-group consisted entirely of students. Those in this age group were distributed across all levels of income and marital status categories. These data suggest that the age cohort effect observed in this study was not strictly the result of young respondents being students or those lacking real-life financial decision-making skills. The age cohort effect observed in this study appears to be generalizable across those aged 25 years of age or younger [4].

\section{Conclusion}

Data used in this study covered an extraordinary time in the history of the US: the one-year period that included the COVID-19 pandemic and resulting economic shutdowns implemented across municipalities and states. A general reduction in aggregate levels of FRT was observed during the peak and subsequent pandemic timeframe, with the most significant decline in FRT levels observed among those who were 25 years of age or younger. As illustrated in Table 7, those who were age 25 or younger represented a wide collection of households. Of course, students were represented; however, this sub-group of respondents also included numerous individuals who were married, employed and well educated. Based on the education and income profile of those in this sub-group, it can be said that these respondents epitomized typical early career households (as well as K-through-12 students, college students and young adults who are beginning their financial life journeys).

\begin{tabular}{|c|c|c|c|c|c|}
\hline & Under 25 & $25-44$ & $45-64$ & Over 65 & \\
\hline Period 0 & 42,023 & 8,889 & 2,717 & 704 & \\
\hline Period 1 & 3,487 & 507 & 176 & 37 & \\
\hline Period 2 & 2,022 & 677 & 191 & 26 & \\
\hline Period 3 & 588 & 236 & 56 & 10 & \\
\hline Period 4 & 5,099 & 1,106 & 273 & 46 & Table 5. \\
\hline Sub-total from Period 2 to 4 & 7,709 & 2,019 & 520 & 82 & Sub-groups by age \\
\hline
\end{tabular}

\begin{tabular}{|c|c|c|c|c|c|}
\hline & Under $25(n=7,709)$ & 25 to $44(n=2,016)$ & 45 to $64(n=520)$ & Over $65(n=82)$ & \\
\hline$b$ (SE) & $-0.01(0.00)^{* *}$ & $0.00(0.01)$ & $-0.01(0.01)$ & $-0.04(0.05)$ & \\
\hline Intercept & 287.49 (83.96) & $-48.85(163.29)$ & 310.88 (322.25) & 873.69 (996.10) & \\
\hline$R^{2}$ & 0.01 & 0.00 & 0.00 & 0.01 & \\
\hline$F$ & $9.66^{* *}$ & 0.22 & 0.77 & 0.72 & \\
\hline \multicolumn{6}{|c|}{ Bootstrapped model with 1,000 replications } \\
\hline$b(\mathrm{SE})$ & $-0.02(0.00)^{* *}$ & $0.00(0.01)$ & $-0.01(0.01)$ & $-0.04(0.05)$ & Table 6. \\
\hline Intercept & $287.49(86.59)^{* *}$ & $-48.84(157.34)$ & $310.88(330.05)$ & 873.69 (1017.48) & Linearity check of \\
\hline$R^{2}$ & 0.00 & 0.00 & 0.00 & 0.01 & financial risk tolerance \\
\hline$\chi^{2}$ & $9.08^{* *}$ & 0.24 & 0.73 & 0.69 & by age sub-groups \\
\hline
\end{tabular}


$\mathrm{RBF}$

13,1

14
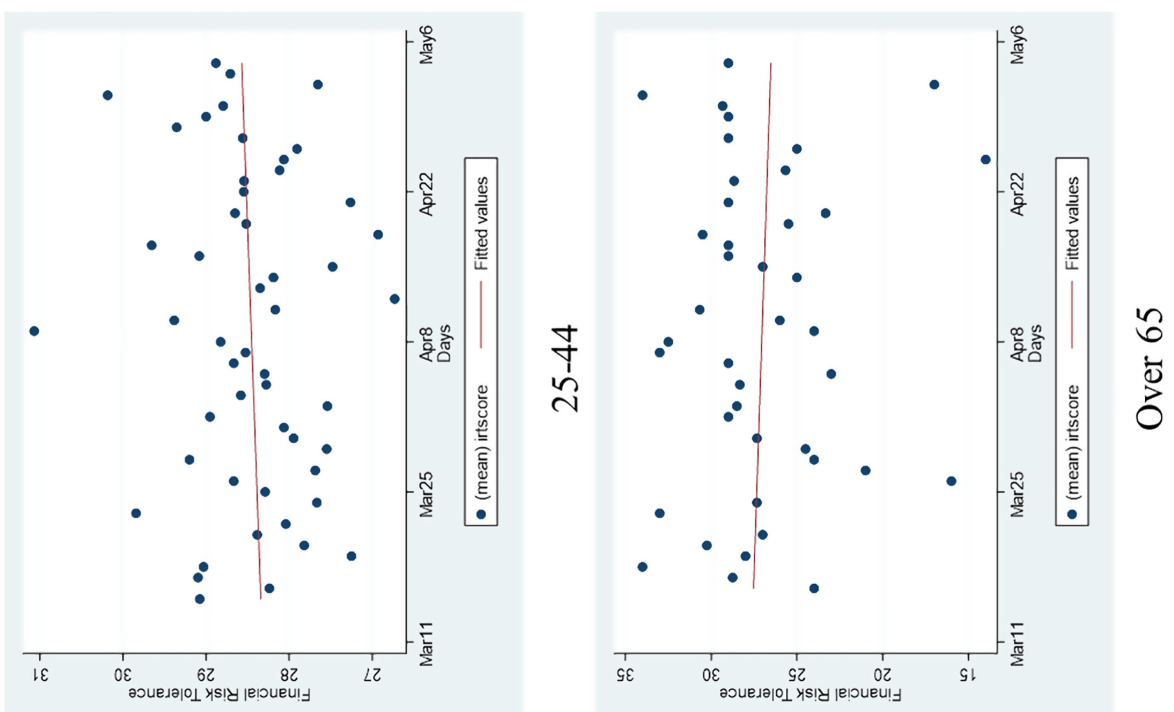

Figure 7.

FRT scores showing a
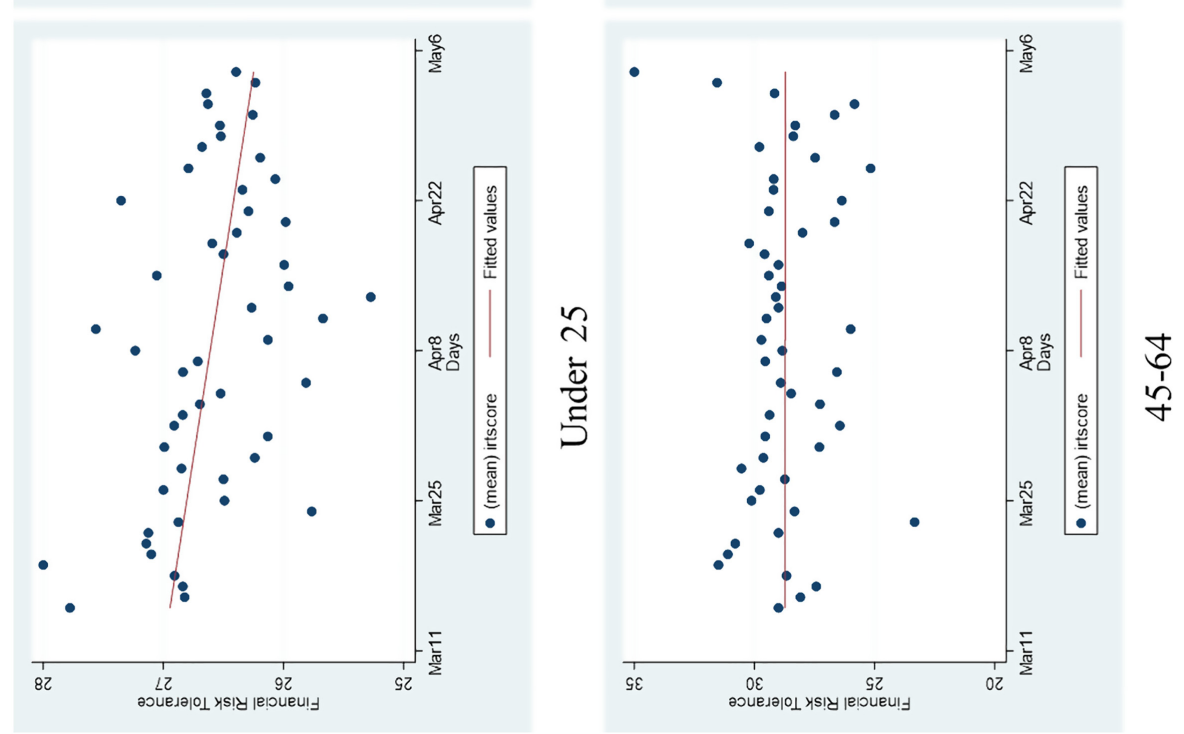

downward tendency

during the COVID19

pandemic across age sub-groups

(aggregated daily average data) 


\begin{tabular}{|c|c|c|c|}
\hline & Frequency & $\%$ & Impact of \\
\hline Gender (male) & 3,804 & 49.40 & \\
\hline \multicolumn{4}{|l|}{ Education } \\
\hline Lower than high school & 3,287 & 42.74 & \multirow{6}{*}{15} \\
\hline High school graduate & 1,970 & 25.61 & \\
\hline Some college & 1,284 & 16.69 & \\
\hline Associate's degree & 305 & 3.97 & \\
\hline Bachelor's degree & 756 & 9.83 & \\
\hline Graduate or higher & 89 & 1.16 & \\
\hline \multicolumn{4}{|l|}{ Household income } \\
\hline$<\$ 25 \mathrm{k}$ & 2,387 & 31.35 & \\
\hline$\$ 25 \mathrm{k}-\$ 50 \mathrm{k}$ & 1,354 & 17.78 & \\
\hline$\$ 50 \mathrm{k}-\$ 75 \mathrm{k}$ & 1,335 & 17.53 & \\
\hline$\$ 75 \mathrm{k}-\$ 100 \mathrm{k}$ & 847 & 11.12 & \\
\hline$>\$ 100 \mathrm{k}$ & 1,692 & 22.22 & \\
\hline \multicolumn{4}{|l|}{ Marital status } \\
\hline Married & 7,224 & 93.81 & Table 7. \\
\hline Never married & 286 & 3.71 & Demographic profile of \\
\hline Living with others & 113 & 1.47 & respondents in the \\
\hline Separated/divorced & 14 & 0.18 & under 25 sub-group \\
\hline Sharing house & 14 & 0.18 & between period 2 and \\
\hline Widowed & 50 & 0.65 & period $4(n=7,709)$ \\
\hline
\end{tabular}

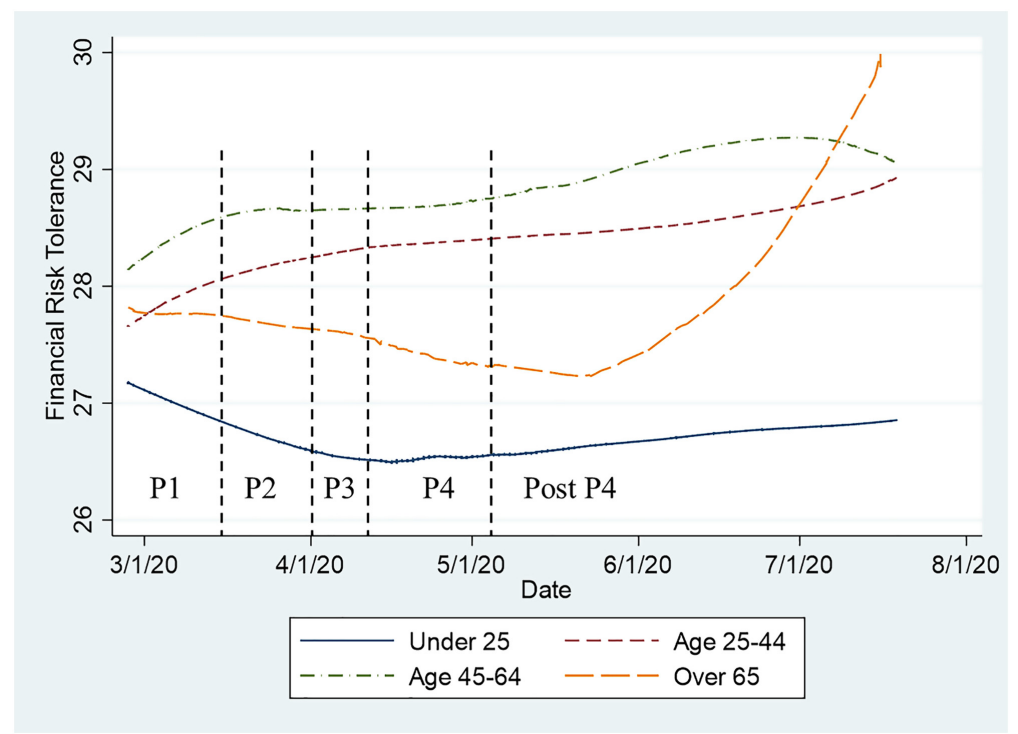

Figure 8. Subsequent average FRT scores by age cohort

While the COVID-19 pandemic, as experienced by those living in the US, had (and continues to have) a significant impact on the way investors and other consumers conceptualized their willingness to take financial risks, the impact was most significant for young people. It is possible that individuals who were old enough to remember the global financial crisis 
$\mathrm{RBF}$

13,1

(and other financial and investment crises [e.g., the 9/11 and Iraqi war scares, the Internet bubble, the crash of 1987, 1970s stagflation, etc.]) reacted differently during the peak moments of the initial pandemic compared to those who were experiencing a financial crisis for the first time.

For young people, the COVID-19 pandemic may have long-term negative outcomes that go beyond worries about health and job security. If the results from this study are indicative of broader changes in risk tolerance, the generalized decline in the willingness to take financial risks does not bode well for the financial capabilities of households in the future. While young people typically lack the financial capability to allocate large percentages of income and net wealth to investing activities, young people do have the time and human capital that allows them to invest more aggressively than households headed by older individuals. It is risktaking activities - driven in part by a willingness to take a financial risk - that leads to greater wealth accumulation. Risk-taking behaviors also drive economic growth. For example, entrepreneurs are considered the main generators of economic growth in the US (Litau, 2018), with risk-taking being considered an essential element of entrepreneurship (Carland et al., 1995; Litau, 2018). If young people have systematically increased their perceptions of risk and reduced their willingness to take financial risk, the wealth accumulation possibilities for those aged 25 or younger may be in jeopardy.

The findings from this study - primarily that in terms of FRT, the COVID-19 pandemic impacted young people disproportionately - suggest that in addition to helping young people feel comfortable in terms of their personal health situation and access to employment and health insurance, policy makers, financial service firms and financial literacy educators should provide information and guidance to young people regarding why being willing to take financial risks is important and how FRT corresponds to the proper functioning of the investment markets. Educational elements should also extend to helping young people understand the mechanisms and advantages and disadvantages associated with the broad array of ways one can take financial risk, including the use of mortgages, credit cards and other forms of debt financing. From a personal finance point of view, younger persons who are in the wealth accumulation stage of their life have the longest time horizon. Based on the findings of this study, it is recommended that young investors be encouraged to continue saving and to take advantage of market volatility as a time to purchase assets at discounted values. Because of their longer time horizon, young people have an opportunity to accumulate greater wealth over their lifespan at potentially lower basis valuations. A dollar-cost averaging (DCA) strategy might work very well for those just beginning their financial life journeys. While such efforts may help young people reevaluate their risk-taking preferences, these types of educational programs may also result in larger societal and economic impacts as young people begin to shift their willingness to take financial risk from pandemic levels to higher levels [5].

While the results from this study are noteworthy, the findings should be considered in the context of certain limitations. For example, while the sample used in the analyses was large and diverse, survey respondents did not represent a US generalizable sample. Instead, the sample represents a relatively well educated and Internet savvy group of investors and consumers from a variety of age, income and marital status backgrounds. Future studies should attempt to replicate the findings from this study with a more representative sample when the next health/financial crisis emerge. It is also important to note that the study utilized data corresponding to the initial identification and spread of COVID-19 in the US. Additional monitoring and analysis is needed to determine if the results reported in this paper hold true if further surges in COVID-19 cases are noted. Even when accounting for these limitations, the findings reported here do provide evidence that the COVID-19 pandemic did have a significant negative impact on the aggregate FRT levels of many Americans. 


\section{Notes}

1. A propensity measure is known to be an effective evaluation tool when the goal of the test is to uncover an investor's subjective estimation of potential outcomes that entail an uncertain risk.

2. A data-driven methodology was used to define the periods. This approach was taken due to the lack of defined and published pandemic interval periods specific to COVID19.

3. During this period, the estimated linear spread of the COVID-19 virus was estimated to be $1,542.31$ $(\mathrm{SE}=4.89)$ new cases each day.

4. Appendix provides an update on the age cohort effects described in this study using additional data from May, June, and July 2020.

5. In this regard, the recently passed Coronavirus Aid, Relief and Economic Security Act of 2020 ("CARES Act") provides a number of provisions that may assist young people weather COVID-19 related financial issues. For example, the "Pandemic Unemployment Assistance Program" ("PUA") provides 39 weeks of benefits to those who lose their employment due to the crisis. Those eligible for PUA include individuals who are self-employed, do not have a sufficient work history to qualify for regular unemployment compensation, and those who have exhausted their rights to regular or extended benefits. The CARES Act allows qualified individuals to withdraw Coronavirus Related Distributions (CRDs) up to $\$ 100,000$ from their qualified defined contribution plan or IRA before age $59 \frac{1}{2}$ without incurring a $10 \%$ early withdrawal penalty or the mandatory $20 \%$ federal tax withholding. The CARES Act also permits a retirement plan to temporarily increase the limit on plan loans to qualified individuals from the lesser of $50 \%$ of a participant's vested account balance or $\$ 50,000$ to the lesser of $100 \%$ of a participant's vested account balance or $\$ 100,000$. This increase is permitted for loans made through September 23, 2020. Effective April 10, 2020, for federal student loans owned by the U.S. Department of Education (including Federal Family Education Loans (FFEL), Federal Direct Loans, and Federal Perkins Loans), payments and interest accrual through September 30, 2020 are automatically suspended. During the suspension period, borrowers are protected from any involuntary collections, wage garnishments, reduction of tax refunds, or federal benefit payments and interest penalties. These CARES Act provisions are by no means exhaustive, but they do provide examples of ways federal policy is attempting to mitigate the negative financial impact of the COVID-19 pandemic. Proper advice and guidance during these turbulent times can assist younger individuals better conceptualize what it means to take a financial risk.

\section{References}

Cardak, B.A. and Martin, V.L. (2019), "Once in a lifetime? The effects of the global financial crisis on household willingness to take financial risk", The Economic Record, Vol. 95 No. 311, pp. 442-461.

Carland III, J.W., Carland Jr, J.W., Carland, J.A.C. and Pearce, J.W. (1995), "Risk taking propensity among entrepreneurs, small business owners and managers", Journal of Business and Entrepreneurship, Vol. 700, pp. 15-06.

CDC (2020a), "Coronavirus disease 2019 (COVID-19)”, available at: https://www.cdc.gov/coronavirus/ 2019-ncov/cases-updates/summary.html.

CDC (2020b), “Cases in the U.S”, available at: https:/www.cdc.gov/coronavirus/2019-ncov/casesupdates/cases-in-us.html.

CDC (2020c), "Pandemic intervals framework (PIF)", available at: https://www.cdc.gov/flu/pandemicresources/national-strategy/intervals-framework.html.

Clarke, R.G. and Statman, M. (1998), "Bullish or bearish?", Financial Analysts Journal, Vol. 54, pp. 63-72.

Gerrans, P., Faff, R.W. and Hartnett, N. (2015), "Individual financial risk tolerance and the global financial crisis", Accounting and Finance, Vol. 55, pp. 165-185.

Grable, J.E. and Lytton, R.H. (1999), "Financial risk tolerance revisited: the development of a risk assessment instrument", Financial Services Review, Vol. 8 No. 3, pp. 163-181.
Impact of

COVID-19 
$\mathrm{RBF}$

13,1

Grable, J.E. and Schumm, W. (2010), "An estimate of the reliability of the Survey of Consumer Finances risk-tolerance question”, Journal of Personal Finance, Vol. 9, pp. 117-131.

Grable, J.E., Lyons, A.C. and Heo, W. (2019), "A test of traditional and psychometric relative risk tolerance measures on household financial risk taking", Finance Research Letters, Vol. 30, pp. 8-13.

Guillemette, M.A. and Finke, M. (2014), "Do large swings in equity values change risk tolerance", Journal of Financial Planning, Vol. 27 No. 6, pp. 44-50.

Guiso, L., Sapienza, P. and Zingales, L. (2013), “Time varying risk aversion”, Working Paper, National Bureau of Economic Research Working Paper No. 19284, available at: https://www.nber.org/ papers/w19284.

Hartnett, N., Gerrans, P. and Faff, R. (2019), “Trusting clients' financial risk tolerance survey scores”, Financial Analysts Journal, Vol. 75 No. 2, pp. 91-104.

Hoffmann, A.O.I., Post, T. and Pennings, J.M.E. (2013), "Individual investor perceptions and behavior during the financial crisis", Journal of Banking and Finance, Vol. 37, pp. 60-74.

Koekemoer, Z. (2018), "The influence of demographic factors on risk tolerance for South African investors", Proceedings of the International Academic Conferences, 6408640, International Institute of Social and Economic Sciences.

Kuzniak, S. and Grable, J.E. (2017), "Does financial risk tolerance change over time? A test of the role macroeconomic, biopsychosocial and environmental, and social support factors play in shaping changes in risk attitudes", Financial Services Review, Vol. 26, pp. 315-338.

Litau, E. (2018), "Entrepreneurship and economic growth: a look from the perspective of cognitive economics", Proceedings of the 2018 9th International Conference on E-business, Management and Economics, pp. 143-147.

Nobre, L.H.N. and Grable, J.E. (2015), "The role of risk profiles and risk tolerance in shaping client decisions", Journal of Financial Service Professionals, Vol. 69 No. 3, pp. 18-21.

Pinjisakikool, T. (2017), "The influence of personality traits on households' financial risk tolerance and financial behavior", Journal of Interdisciplinary Economics, Vol. 30, pp. 32-54.

Rabbani, A.G., Grable, J.E., Heo, W., Nobre, L. and Kuzniak, S. (2017), "Stock market volatility and changes in financial risk tolerance during the Great Recession”, Journal of Financial Counseling and Planning, Vol. 28 No. 1, pp. 140-154.

Rabbani, A., O’Neill, B., Lawrence, F. and Grable, J. (2018), “The investment risk tolerance assessment: a resource for extension educators", Journal of Extension, Vol. 56 No. 7, 7TOT4.

Reidy, C. (2013), "Cogent research: many consumers use social media to help make investment decisions", Boston Globe, Vol. 22, February, available at: https://www.bostonglobe.com/ business/2013/02/22/cogent-research-many-consumers-use-social-media-help-make-investmentdecisions/gn8c7Q1AJT7ccMgbU36xiO/story.html.

Robbins, T. (2014), Money: Master the Game — 7 Simple Steps to Financial Freedom, Simon \& Schuster, New York.

University of Virginia Library (2020), "Using and interpreting Cronbach's alpha”, available at: https:// data.library.virginia.edu/using-and-interpreting-cronbachs-alpha/.

Van de Venter, G., Michayluk, D. and Davey, G. (2012), "A longitudinal study of financial risk tolerance”, Journal of Economic Psychology, Vol. 33, pp. 794-800.

Vogenberg, F.R. and Cutts, S. (2009), "Economic instability and its impact on decision making in health care", Pharmacy and Therapeutics, Vol. 34, pp. 24-25.

Walls, M.R. and Dyer, J.S. (1996), "Risk propensity and firm performance: a study of the petroleum exploration industry", Management Science, Vol. 42, pp. 1004-1021.

Wang, H. and Hanna, S.D. (1998), "Does risk tolerance decrease with age?", Financial Counseling and Planning, Vol. 8 No. 2, pp. 27-31. 
Yao, R. and Curl, A.L. (2011), "Do market returns influence risk tolerance? Evidence from panel data", Journal of Family and Economic Issues, Vol. 32, pp. 532-544.

Yao, R., Hanna, S.D. and Lindamood, S. (2004), "Changes in financial risk tolerance, 1983-2001", Financial Services Review, Vol. 13, pp. 249-266.

\begin{abstract}
Appendix
An additional robustness check was made using data from May, June, and July 2020 (i.e., periods following the initial data analysis). Data from these months represented a period of time that represented a general reopening of the US economy and a rebound in US stock market averages. The purpose of the test was to ensure that the age cohort findings reported in this paper were valid, given the changing economic environment. In Figure 8, P1, P2, P3, and P4 represent the periods of analysis in the paper. Data for the robustness check are represented by the Post $\mathrm{P} 4$ period. As shown in Figure 8, a slight increase in FRT was noted across age cohorts (i.e., Post P4), with the largest increase in the willingness to take risk being observed among those over the age of 65 . While there was a slight increase in FRT scores among those under the age of 25, the increase was not significant. Even after accounting for the increase, the average July 2020 FRT score for those 25 years of age or younger was below the average pre-COVID-19 FRT score.
\end{abstract}

\title{
Corresponding author
}

Wookjae Heo can be contacted at: wookjae.heo@sdstate.edu

For instructions on how to order reprints of this article, please visit our website: 